\title{
"La cueva de Monte Virgen, Chalchinuitán, Chiapas: un espacio SAGRADO NATURAL DE CONTINUIDAD CULTURAL PREHISPÁNICA," de Thomas Arvol Lee Whiting
}

\author{
"The Cave of Monte Virgen, Chalchihuitán, Chiapas: a Natural Sacred Space of pre-Hispanic Cultural \\ Continuity," of Thomas Arvol Lee Whiting
}

Víctor Manuel Esponda-Jimeno

$\mathrm{D}$ esde los años ochenta, Thomas Arvol Lee Whiting tuvo la intención de dar a conocer la información que ahora se publica. En 1984 elaboró un borrador para presentarlo en un homenaje que yo estaba organizando para Calixta Guiteras, el cual no se concretó por motivos que no viene al caso referir. En esa ocasión, la versión de su trabajo quedó inconclusa, aunque me hizo saber que su cometido era completar el escrito, pues tenía la intención de visitar el sitio para explorarlo y mapear la pequeña oquedad en la que se encontraron las esculturas. No consiguió ese propósito y por algunos años abandonó el manuscrito. En 1990, cuando yo estaba organizando otro homenaje, esa vez para Alfonso Villa Rojas, Tom, por mi invitación expresa, retomó su borrador para retrabajarlo, pero no avanzó mucho en él y no lo presentó. Transcurrido el tiempo, le preguntaba con frecuencia cuándo tendría terminada la versión de las "máscaras" de Chalchihuitán, a lo que respondía que se daría espacio para "echarle mano". Sin embargo, por lo que se aprecia en el presente texto, quedó en calidad de informe, pues no tuvo ocasión de acceder al sitio para ampliar su perspectiva ni analizar directamente las esculturas que muchas veces llamó máscaras.

Víctor Manuel Esponda Jimeno, Centro de Estudios Superiores de México y Centroamérica de la Universidad de Ciencias y Artes de Chiapas, México.
Es claro que una exploración del sitio hubiera arrojado información complementaria dado que no sabemos qué más había en esa cueva: icuál era su entorno y contexto?, ¿había acaso restos cerámicos, vestigios de ofrendas $u$ otros elementos?, irealmente fue un recinto funerario?, ¿qué evidencias lo soportan?, ise observaron osarios o urnas? A lo señalado debe agregarse que no se cuenta con información etnográfica directamente relacionada con el sitio y que se desconoce si el lugar era considerado sagrado. Estas interrogantes quedan pendientes de respuesta.

Desde el punto de vista etnológico pueden presentarse algunas consideraciones generales en torno a las piezas encontradas. Esculturas de este tipo se hallan en diversas partes del mundo "primitivo", y en la mayoría de los casos su presencia está asociada a cultos individuales. En principio no son máscaras, sino rostros rústicos suigeneris, manufacturados a guisa de pequeños tótems, o quizás fetiches, que cuentan con una espiga o mango — asa - ya para sujetarse con las manos o para fijarse en un lugar determinado. Este último parece que fue el propósito de los mangos que presentan las cabezas que estaban en Monte Virgen.

Su talladura es muy elemental y es claro que las hicieron uno o varios individuos poco instruidos en

Recibido: 08 de abril de 2013. 
el arte de la escultura y apoyados con pocos recursos tecnológicos. Seguramente quisieron continuar una vieja tradición de determinado culto dirigido a seres especiales o a ancestros memorables — con seguridad antes representados en esculturas de piedra o barro-. Opino que el lugar se trataba de un "tabernáculo de culto particular" que cuando se saqueó ya estaba en desuso, pues de haber tenido vigencia y ostentar el carácter de santuario no se hubiera permitido su profanación.

Las esculturas halladas en Monte Virgen tienen cierta analogía con las que se manufacturaban en África, Sudamérica, el norte de México y América del Norte. Si se las observa con detalle, se asemejan en ciertos rasgos a las cabezas de la Isla de Pascua y a algunas tallas elaboradas por nativos de Sudamérica. Con esto no se quiere insinuar que su difusión fuera amplia; más bien, el caso de Chalchihuitán se trata de una manifestación aislada, pues en Chiapas son pocas las antiguas esculturas de madera que se han encontrado.

Respecto a su antigüedad, también coincido en que pudieron haberse elaborado en cualquier momento después de la conquista española, entre el siglo XVII y el XIX, cuando el uso de herramientas metálicas era ya bastante común. Puede caber la posibilidad de que las piezas se hayan facturado en distintos momentos dado que no se conoce el fechamiento de la madera. Debe considerarse un nuevo análisis, pues ignoramos si las piezas fueron elaboradas a partir del mismo árbol o si estuvieron expuestas a condiciones de humedad y a la rapacidad de insectos.
Es pues evidente que las esculturas de Monte Virgen no son prehispánicas, aunque lo cierto es que expresan una antigua tradición de imaginería que se ubica en casi toda América. Algunas de dichas imágenes se concibieron como máscaras y otras como figuras o ídolos - deidades o personajes trascendentes, benévolos o malvados-. Las esculturas de Chalchihuitán ciertamente son de burda manufactura, pero reflejan un singular estilo de la presencia humana al inmortalizarla a través de la naturaleza inanimada que simboliza a seres especiales - y sin duda, también comunes- que no necesariamente se apegan a los modelos estéticos de anatomía occidental - simetría, forma, proporción o distribución - y que concretan la idea de la imagen humana en una de sus partes más representativas, la cabeza, parte rectora de nuestra anatomía donde se sitúan, además del cerebro, los principales sentidos, referentes fundamentales de todas nuestras acciones y abstracciones. En particular, los rostros — sinónimo de filiación- son fundamentales en todas las civilizaciones y la nuestra es quizás una de las más obsesionadas en ello - fotografías, pinturas, videos-. Para el caso que nos ocupa, las "máscaras" de Monte Virgen, si a Franz Boas (1897, en Bohannan y Glazer, 1993: 88) le asistió la razón al referirse a ese tema, puede que hayan servido para "asustar a los espíritus hostiles". O quizás fueron "imágenes conmemorativas", y me aventuro a sugerir que tal vez fueron guardianes de la cueva y del cerro que le es propio, mas esto sólo queda en el terreno de la especulación. 


\section{La cueva de Monte Virgen, Chalchihuitán, Chiapas: un espacio sagrado natural de continuidad cultural prehispánica}

\section{Thomas Arvol Lee Whiting $\nmid$}

\section{Antecedentes}

En 1960, las 14 cabezas antropomorfas de madera abordadas en el presente artículo fueron sustraídas de la cueva llamada Monte Virgen, paraje Emiliano Zapata, municipio de Chalchihuitán, Chiapas, por el fotógrafo estadounidense de origen turco Tugrul Uke, quien residía en aquel entonces en San Cristóbal de Las Casas, Chiapas. El saqueo fue debidamente denunciado por dos antropólogos extranjeros comprometidos con las investigaciones etnográficas en Los Altos de Chiapas y las cabezas fueron formalmente recuperadas por la Justicia federal de México. A pesar de su falta de preparación en ciencias sociales, Uke tomó una foto de las cabezas in situ (ver figura 1), un importantísimo dato al que se refiere parte del testimonio que se cita más abajo.

Para contextualizar mejor los hechos, y dado que se trata de datos únicos proporcionados por un testigo presencial, cito a continuación in extenso una parte del artículo de William Holland (1960: 127-129, láminas I y II) donde reporta los hechos tal como sucedieron a principios de la década de los años sesenta:

Un importante eslabón con el pasado se descubrió recientemente en el pináculo de una montaña en el municipio de Chalchihuitán, el más aislado. Se trata de una comunidad tzotzil 100\% monolingüe, en Los Altos de Chiapas, localizada a unos 25 kilómetros de Larráinzar. En mayo de 1960, el Sr. Tugrul Uke, fotógrafo estadounidense ambulante que por esos días estaba viviendo en San Cristóbal de Las Casas, subió a la montaña denominada "Monte Virgen", situada en el rancho del Sr. Antonio Navarro. Él y su grupo, con la ayuda de guías indígenas, pudieron localizar una cueva poco profunda, ubicada cerca de la cima de la montaña y que contenía ídolos de madera. Aunque el Sr. Uke carece de preparación científica y de interés por el contenido cultural de los ídolos, tuvo buen cuidado de fotografiar las piezas in situ (lám. I [ver figura 1]) antes de saquear el lugar y repartirse el contenido entre él y sus compañeros. ${ }^{1}$

Como es costumbre en tan lamentables situaciones, no se recogieron datos etnográficos de ninguna clase, bien que otros informantes justificaron el alegato del Sr. Uke de que ese lugar había dejado de utilizarse para fines ceremoniales. Aunque el Sr. Uke afirma que había algunas piezas más, un examen cuidadoso de la fotografía revela un total de trece ídolos. El que esto escribe se inclina a creer que éste era su número exacto. Los ídolos eran de dos tipos (lám. II [ver figura 2]) y sin duda de origen post-hispánico, como lo prueban los cortes de madera de su manufactura.

Aunque nunca se ha realizado ninguna investigación sistemática de este sitio, cuando se le estudie a la luz de los materiales de Larráinzar es probable que el "Monte Virgen" sea considerado como una ch'iebal en algún tiempo de la historia reciente. Se mencionó como una de las montañas sagradas de los sanandreseros, y sin duda alguna debió efectuarse ahí procesiones de curación similares a las descritas para Larráinzar y Zinacantán. Los ídolos de madera, reemplazados actualmente por cruces en otras partes, pueden representar a los trece petometik y kuchometik, las deidades del linaje, cuyos nombres se invocan tan a menudo en los rezos de curación ${ }^{2}$ de Larráinzar. Las ofrendas pudieron ser muy semejantes a las que todavía hoy son comunes en toda el área, pero el rasgo de colocar incienso en los ojos y en la boca de

† Thomas Arvol Lee Whiting (1933-2013), Centro de Estudios Superiores de México y Centroamérica de la Universidad de Ciencias y Artes de Chiapas, México. 
los dioses es completamente prehispánico en la tradición maya.

De acuerdo con el Sr. Uke y otros informantes que subieron a la cima, hay considerables fundamentos para pensar que alguna vez fue cementerio. Sacando nuevamente inferencias de los datos de Larráinzar, este lugar pudo ser un cementerio para los miembros más importantes del linaje, especialmente aquellos ancianos cuyos animales guardianes habían alcanzado ya el nivel decimotercero de la ch'iebal. Esta práctica puede estar relacionada con el antiguo concepto maya yucateco de que había una ceiba gigantesca que creció exactamente en el centro de la tierra y atravesó los centros de los diversos niveles del cielo (Tozzer, 1907: 154). La selección de este lugar para inhumaciones de gente importante hizo posible que sus espíritus ascendieran al cielo y con el tiempo ocupar un lugar más alto.

El Sr. Uke tuvo la amabilidad de proporcionar al autor la fotografía de los ídolos in situ (lámina I [ver figura 1]), como un regalo personal. Sin embargo, debido al incidente antes mencionado retiró el permiso para usarla y ha pedido se la devuelva, alegando exclusividad de derechos de reproducción. Aparece aquí, por consiguiente, expresamente contra sus deseos y únicamente con fines científicos (Holland, 1960: 127-129, láminas I y II).

\section{Localización de la cueva}

La cueva Monte Virgen está localizada en la cima de un cerro en la esquina suroeste de la cabecera municipal de Chalchihuitán. Por problemas de tenencia de la tierra con el municipio colindante de Chenalhó, no hemos podido conseguir permiso para penetrar a Chalchihuitán y mapear la cueva y el área que la circunda.

\section{Datación de las cabezas}

Tal como señala Holland (1960), las cabezas parecen ser, por su manufactura, poshispánicas. Sin embargo, en 1984, la Dirección del Centro Regional del INAH mandó la punta de la espiga de una de las cabezas, la número 5, como muestra para análisis de carbono 14 , dando como resultado una fecha de \pm 5568 que, convertida, da una fecha de $726, \pm 36$ d.c. En otro oficio a Carlos Silva Rohads del día 22 de agosto de 1989, la fecha fue modificada ligeramente a 725 , \pm 40 d.c. Estas fechas, no muy diferentes entre sí, no concuerdan para nada con la evaluación que hicimos Gareth W. Lowe y el que esto escribe para el Ministerio Público, según la cual habrían pasado menos de 100 años desde que se fabricaron las cabeza.

Parte del problema reside en la muestra que el INAH mandó para fechar. Por falta de conocimiento o descuido, se envió la punta de la espiga, es decir, el corazón de la pieza de madera o la parte más antigua, y no se envió la parte más exterior, que en este caso sería la oreja de la cabeza, por lo que es natural que la fecha indicada no se aproxime a la de la muerte del árbol que sirvió como fuente de madera para la escultura, sino que sea mucho más temprana. Esta datación es válida para la edad del árbol, pero no tiene nada que ver con la fecha de la hechura y uso posterior de las cabezas. Además, no se sabe si para tallar la pieza fue escogido un pedazo de madera seca y muerta hace años, o si el trozo fue cortado cuando el árbol estaba vivo, de tal manera que en ese momento terminó su crecimiento, y así se realizó su registro anual de crecimiento y se dató la fecha de su muerte.

Como quiera que sea, personalmente no estoy convencido de que la estimación de la fecha de fabricación que dimos Lowe y yo al Ministerio Público sea la correcta. Ambos estábamos de acuerdo en que las piezas parecían haber sido talladas con herramientas de metal y en esto basamos nuestro dictamen original; pero ahora no creo que la fecha fuera tan reciente. Supongo que las cabezas se hicieron en cualquier momento después de la conquista española, pero probablemente antes del siglo XVIII o XIX, ya que algunas están bastante desgastadas y erosionadas y la madera es de una especie muy dura que resistiría mucho la 
erosión. La madera de la Cabeza 5 que se mandó al Departamento de Prehistoria del INAH es de la especie Cordia dodecandra $D C$, de la familia Boragináceas, y su nombre común en Chiapas es cupapé (oficio 401.13.224 de fecha 20 de agosto de 1984). Faustino Miranda describe la madera de la siguiente forma:

es considerada como excelente para muebles finos y tornería. El corazón es color de tabaco con vetas negruzcas irregulares, duro, pesado (unos 26 kilos por pie cúbico o 919 kilos por metro cúbico) y fuerte; se trabaja con facilidad y adquiere buen pulimento. Localmente se usa para incrustaciones, costillas y fustes de silla de montar, sillas, durmientes para trapiches, etcétera (Miranda, 1998: 243-4).

Descripción de las cabezas

\section{Cabeza 1}

Descripción: cabeza humana con espiga (figura 3a). Material: madera pesada, café oscuro. Especie: Cordia dodecandra $D C$, probable.

Medidas: alto, 46 centímetros; ancho, 19 centímetros; grueso, 12.5 centímetros; largo de la cara, 24 centímetros.

Forma facial: la cara es larga, rectangular, con la frente un poco más ancha que la mandíbula. Hay un poco de relieve facial alrededor de los labios y mejillas. La nariz es larga y recta, casi sin aspecto natural. La cabeza está plana por detrás.

Elementos faciales: ojos rectangulares hondos, rellenos de una sustancia blanca bajo las cejas, las cuales son rectas, pesadas y hondas. La boca es rectangular, de hendidura profunda, rellenada con resina blanca y pedazos de concha y madreperla. Las orejas son vestigios angulares y rectos en forma de L, con un agujero cuadrado cortado en la parte inferior para adornarlo con aretes. Los agujeros fueron hechos con un formón angosto. Los ojos y boca fueron grabados hondos y cuadrados con el fondo plano.
Técnica: grabado y raspado. La presencia de muchas concavidades pequeñas muy leves demuestra que la cabeza fue hecha con formón, sin ser limada o pulida, solamente raspada.

Condición: el fondo de la espiga y el de la cabeza, especialmente cerca de la orilla posterior, están carcomidos por insectos y por la erosión. Como se ve en la fotografía in situ, las cabezas estaban paradas sobre espigas e inclinadas hacia atrás, descansando sobre la pared de la cueva.

Nota: el largo facial fue tomado de la parte superior de la frente hasta la punta de la barbilla.

\section{Cabeza 2}

Descripción: cabeza humana con espiga (figura 3b). Material: madera pesada, café oscuro, igual que en la Cabeza 1. Especie: Cordia dodecandra DC, probable. Medidas: alto, 62.3 centímetros; ancho, 15 centímetros; grueso, 10 centímetros; largo de la cara, 27 centímetros.

Forma facial: la cara es larga y delgada, con la frente un poco más ancha que la mandíbula. Hay poco relieve facial natural; solamente alrededor de los labios, mejillas y barbilla hay un ligero relieve. La nariz es larga y recta, sin casi aspecto natural, un poco más ancha en la punta que en el puente. La parte trasera de la cabeza es plana.

Elementos faciales: Ojos ovalados grabados, hondos y rellenos de una sustancia blanca debajo de las cejas, las cuales son rectas, pesadas y hondas. La boca es rectangular, hondamente excavada y rellenada con resina blanca, pedazos de concha y madreperla. Las orejas son angulares y rectas en forma de L, con un agujero cuadrado cortado en la parte inferior para adornarlas con aretes. Los agujeros fueron hechos con un formón angosto. Los ojos y la boca fueron grabados, hondos y cuadrados con el fondo plano.

Técnica: grabado y raspado. Muchas concavidades pequeñas y muy leves demuestran que la cabeza fue hecha con formón, sin ser limada o pulida, solamente raspada. 
Condición: el fondo de la espiga y de la cabeza, especialmente cerca de la orilla posterior, están carcomidos por insectos y por la erosión. Como se ve en la fotografía in situ, las cabezas estaban paradas sobre la espiga e inclinadas hacia atrás descansando sobre la pared de la cueva. La cabeza en casi toda su superficie está mal preservada, pues el agua y los insectos han carcomido mucho de su superficie, dejándola rugosa e irregular.

Nota: El largo facial fue tomado desde la parte superior de la frente hasta la punta de la barbilla.

\section{Cabeza 3}

Descripción: cabeza humana con espiga (figura 3c). Material: madera, café oscuro, pesada, igual que en la Cabeza 1. Especie: Cordia dodecandra DC, probable.

Medidas: alto, 45 centímetros; ancho, 13 centímetros; grueso, 8 centímetros; largo de la cara, 26 centímetros. Forma facial: cara larga y muy angosta. Cejas arqueadas hondamente.

Elementos faciales: ambos ojos son ovalados, llenos de la sustancia blanca. La boca es rectangular y también tiene material blanco en ella. La boca cuelga de un lado pero, como el grano de la madera está roto en esta área, puede ser que a esto se deba la forma de la boca, y no al estilo. Las orejas son largas, con perfil cuadrado de frente. Las orejas tienen pequeños agujeros cuadrados para aretes en el extremo inferior. La parte trasera de la cabeza ha sido cortada varias veces con un machete.

Técnica: grabado y raspado. Ojos y boca grabadas hondamente y en forma cuadrada.

Condición: la superficie original está pobremente preservada sobre el lado derecho.

\section{Cabeza 4}

Descripción: cabeza humana con espiga (figura 3d). Material: madera, café oscuro, pesada, igual que en la Cabeza 1. Especie: Cordia dodecandra DC, probable.
Medidas: alto, 52 centímetros; ancho, 15 centímetros; grueso, 7.5 centímetros; largo de la cara, 23 centímetros.

Forma facial: la cara es rectangular; la frente, las mejillas y la quijada son planas.

Elementos faciales: los ojos y la boca están hondamente grabados y son rectangulares en su forma. El ojo izquierdo y la boca tienen la sustancia blanca en su interior. La frente es pesada y recta. La quijada es puntiaguda. La nariz es lisa y sencilla. Las orejas tienen forma de gancho y un agujero de forma cuadrada en la orilla inferior hecho con formón angosto.

Técnica: grabado y raspado. Los ojos y la boca están grabados profundamente y son cuadrados.

Condición: la parte superior de la cabeza, la cara y la tercera parte inferior de la espiga están erosionadas. En la cima de la cabeza hay siete marcas hechas con un instrumento filoso. Todas las marcas miden de cinco a ocho milímetros entre sí. No son cortadas recientes.

\section{Cabeza 5}

Descripción: cabeza humana con espiga (figura 3e). Material: madera, café oscuro, pesada, igual que en la Cabeza 1. Especie: Cordia dodecandra DC, probable.

Medidas: alto, 43 centímetros; ancho, 13 centímetros; grueso, 11.5 centímetros; largo de la cara, 30 centímetros.

Forma facial: la frente está aplanada verticalmente, pero es curva hacia los laterales.

Elementos faciales: cara larga y angosta. Boca grande grabada abierta. No tiene rectos los costados de la boca como en las otras cabezas; no hay líneas rectas o cuadradas. Los ojos están hechos en la misma forma abierta. Los ojos y la boca tienen evidencia de la sustancia blanca. La ceja, baja, tiene muy poco o nada de concavidad facial entre mejillas, boca y labios. La quijada es ancha y prominente. Las orejas son pequeñas proyecciones con un agujero redondo taladrado en ellos, casi por la mitad. 
Técnica: grabado y raspado.

Condición: la parte trasera de la cabeza y el lado izquierdo de la cara están muy erosionados.

\section{Cabeza 6}

Descripción: cabeza humana con espiga (figura 4a). Material: madera, café oscuro, pesada, igual que en la Cabeza 1. Especie: Cordia dodecandra DC, probable.

Medidas: alto, 31 centímetros; ancho, 11 centímetros; grueso, 7 centímetros; largo de la cara, 27 centímetros. Forma facial: cara larga y angosta, casi tubular. Elementos faciales: ojos y boca profundos, hechos en forma abierta. Nariz larga y angosta. Honda marcación entre mejillas, labios y boca, la cual inicia en la esquina de la nariz y se extiende hacia abajo y fuera de la mandíbula, debajo de la mejilla.

Técnica: probablemente grabada y raspada.

Condición: muy erosionada; no hay superficie original. Parece la cabeza más vieja de las 14, según indica el hecho de que sea la peor preservada.

\section{Cabeza 7}

Descripción: cabeza humana con espiga (figura 4b). Material: madera, café oscuro, pesada, igual que en la Cabeza 1. Especie: Cordia dodecandra DC, probable.

Medidas: alto, 50.5 centímetros; ancho, 13.5 centímetros; grueso, 9.5 centímetros; largo de la cara, 30 centímetros.

Forma facial: cara larga y angosta con sección oval. Elementos faciales: la frente es baja y curva en los lados. Los ojos son agujeros elípticos. El ojo izquierdo y la boca todavía tienen evidencia de sustancia blanca en ellos. La oreja derecha está presente y parece que tuvo un agujero por la orilla inferior, donde se fijaba un arete. La oreja izquierda ha sido removida por varios golpes de machete. Los cortes de machete parecen ser recientes. La boca está grabada en un estilo abierto, pero hondo.
Técnica: grabado y tal vez raspado, elaborado de forma rústica.

Condición: mala preservación; la superficie original sólo la vemos sobre la mejilla derecha. En la parte trasera de la cabeza hay un agujero cóncavo de tres centímetos de diámetro que tiene un centímetro de profundidad.

\section{Cabeza 8}

Descripción: cabeza humana con espiga (figura 4c). Material: madera, café oscuro, pesada, igual que en la Cabeza 1. Especie: Cordia dodecandra $D C$, probable.

Medidas: alto, 56.5 centímetros; ancho, 18.5 centímetros; grueso, 8.5 centímetros; y largo de la cara, 24 centímetros.

Forma facial: cara plana, mejillas y frente amplias. Elementos faciales: los ojos son hondos y rectangulares, llenos de la sustancia blanca. Boca rectangular y honda, llena de la sustancia blanca. Orejas en forma de gancho con agujeros cuadrados en su orilla inferior. La orilla superior de las orejas coincide, horizontalmente, con la línea de la frente. La parte trasera de la cabeza está plana de oreja a oreja, y desde arriba de la cabeza hasta el fondo de la misma.

Técnica: grabado y raspado.

Condición: cabeza pobremente preservada en general; la cara está muy erosionada y gastada por el agua. La superficie original solamente se encuentra sobre la mejilla derecha. Sobre la parte de atrás de la cabeza se encuentran dos incisiones superficiales de 2.5 centímetros de largo y separadas por un centímetro, las cuales fueron hechas por un instrumento metálico filoso. La punta de la espiga está erosionada y la madera craquelada.

\section{Cabeza 9}

Descripción: cabeza humana con espiga (figura 4d). Material: madera, café oscuro, pesada, igual que en la Cabeza 1. Especie: Cordia dodecandra DC, probable. 
Medidas: alto, 65.5 centímetros; ancho, 11 centímetros; grueso máximo, 8 centímetros; largo de la cara, 26.5 centímetros.

Forma facial: cara larga y angosta con una sección oval. La cara tiene un perfil plano y la frente tiene una ligera curva vertical.

Elementos faciales: las orejas son chicas, de forma tabular, colocadas a mitad de la cabeza. Los ojos son concavidades grandes y abiertas en forma de óvalo y de poca profundidad, ya que sus detalles han desaparecido con la erosión. La boca está abierta como un gran óvalo, pero más rectangulary superficial que los ojos. Dos grandes depresiones se encuentran debajo de cada oreja y sobre la parte trasera de la cabeza. Técnica: grabado.

Condición: altamente erosionada. La superficie original no está presente en ninguna parte de la cabeza.

\section{Cabeza 10}

Descripción: cabeza humana con espiga (figura 4e). Material: madera, café oscuro, pesada, igual que en la Cabeza 1. Especie: Cordia dodecandra DC, probable.

Medidas: alto, 59.5 centímetros; ancho, 15.5 centímetros; grueso máximo, 10 centímetros, largo de la cara, 27 centímetros.

Forma facial: cara larga en forma de óvalo.

Elementos faciales: los ojos y la boca están grabados en estilo profundo rectangular y aún tienen restos de la sustancia blanca. Las orejas son grandes y gruesas, en forma de gancho, con agujeros alrededor, en la parte inferior. La parte trasera de la cabeza está plana, vertical y horizontalmente. La frente también está plana.

Técnica: grabado y raspado.

Condición: los costados de la cara y de la espiga están altamente erosionados y carcomidos por insectos. Sobre la parte posterior de la cabeza hay tres líneas o ranuras hechas por un formón. Varias marcas de formón - siete en una línea- forman las ranuras, resultando en una línea muy trabajada.

\section{Cabeza 11}

Descripción: cabeza humana con espiga (figura 4f). Material: madera, café oscuro, pesada, igual que en la Cabeza 1. Especie: Cordia dodecandra DC, probable.

Medidas: alto, 59 centímetros; ancho, 13.5 centímetros; grueso máximo, 4 centímetros; largo de la cara, 25 centímetros.

Forma facial: largo rectángulo.

Elementos faciales: ojos y boca grabados en estilo hondo, con cortes rectos y escuadras, ambos con restos de la sustancia blanca. Parece que las orejas tenían forma de gancho, pero están muy destruidas. Técnica: grabado.

Condición: la cabeza fue muy dañada por cortes de machete que eliminaron casi todos los detalles de la frente. La parte de atrás fue aplanada también por cortes de machete - ver más adelante la sección "Etnografía y datos arqueo-históricos relacionados", donde se mencionan las razones por las que esta pieza fue destruida.

\section{Cabeza 12}

Descripción: cabeza humana con espiga (figura 5a). Material: madera, café oscuro, pesada, igual que en la Cabeza 1. Especie: Cordia dodecandra DC, probable.

Medidas: alto, 63 centímetros; ancho máximo, 14.5 centímetros; grueso máximo, 8 centímetros; largo de la cara, 28 centímetros.

Forma facial: cara larga en forma de rectángulo, con la barba un poco más delgada que la frente. La cara tiene poco relieve natural.

Elementos faciales: ojos de media luna profundos, con algo del material blanco en ellos. El ojo izquierdo tiene un pedazo de concha o madreperla pegado en una esquina. La boca está grabada con profundidad en forma rectangular, con la sustancia blanca dentro. La nariz es larga con forma de triángulo. La barba es plana verticalmente desde los labios hasta la punta de la quijada, pero tiene una curva en los lados. 
Técnica: grabado y raspado.

Condición: bien preservada, aunque la parte trasera superior de la cabeza está mal preservada, así como la punta de la espiga.

\section{Cabeza 13}

Descripción: cabeza humana con espiga (figura 5b). Material: madera, café oscuro, pesado, igual que en la Cabeza 1. Especie: Cordia dodecandra DC, probable.

Medidas: alto, 61 centímetros; ancho máximo, 17 centímetros; grueso máximo, 8 centímetros; largo facial, 26 centímetros.

Forma facial: larga, con forma de rectángulo. La frente tiene una ligera curva convexa lateralmente y es plana verticalmente. Atrás, la cabeza está plana, tanto vertical como horizontalmente.

Elementos faciales: los ojos son de forma rectangular y están grabados con profundidad, con material blanco en ellos. La nariz es un triángulo largo, es recta y plana desde el frente hasta su punta. La boca es un rectángulo hondo y está llena de la sustancia blanca, con una pieza de concha aún pegada en su lugar. Hay algo de relieve facial. Las mejillas están ligeramente levantadas, el labio inferior se extiende hacia afuera y hay una ligera curva entre el labio y la punta de la barba. Las orejas tienen forma de gancho, con un pequeño agujero cuadrado cortado en la orilla inferior con un formón angosto.

Técnica: grabado y raspado.

Condición: la cabeza presenta su superficie original en todas sus partes, pero la punta de la espiga está erosionada; en la misma condición se encuentra la parte trasera de la cabeza.

\section{Cabeza 14}

Descripción: cabeza humana con espiga (figura 5c). Material: madera, café oscuro, pesada, igual que en la Cabeza 1. Especie: Cordia dodecandra DC, probable.
Medidas: alto, 58.5 centímetros; ancho máximo, 15 centímetros; grueso máximo, 8 centímetros; largo de la cara, 26 centímetros.

Forma facial: larga, en forma de rectángulo ligeramente reducido desde la frente hasta las mejillas. La parte trasera de la cabeza está plana. La frente es cóncava verticalmente y convexa lateralmente.

Elementos faciales: Ios ojos tienen forma de rectángulos y están hondamente cortados, llenos de la sustancia blanca. Una marca en el ojo derecho es una impresión de mosaico. La frente está hondamente cortada. La nariz tiene forma de un corto triángulo. La boca es rectangular, está grabada y llena de la sustancia blanca. Las orejas tienen forma de gancho, con agujeros cuadrados cortados en la orilla inferior. La cara es plana verticalmente y ligeramente convexa en los laterales. La cabeza no está centrada sobre la espiga.

Técnica: grabado y raspado.

Condición: hay algo de la superficie original sobre la cara, especialmente sobre la mejilla, el ojo y la oreja derecha. La espiga ha sido quemada en su punta, probablemente por las ofrendas de velas colocadas cerca.

\section{Etnografía y datos arqueo-históricos relacionados}

En la amplia colección de cultura material de Los Altos de Chiapas que contiene el Museo Na Bolom, fundado por Frans Blom y Gertrude Duby en San Cristóbal de Las Casas, se encuentra un fragmento de jicalpestle antiguo que tiene relevante asociación directa con las cabezas de madera reportadas aquí, ya que proviene de la misma cueva Monte Virgen. Fue obtenido por el mismo individuo y probablemente en el mismo viaje. La tarjeta de adquisición museográfica de Na Bolom dice:

Fragmento de vasija de jícara pintada encontrado por Tugrul Uke cerca del abrigo rocoso ahora nombrado Na-Ku-Che (Casa de los Dioses de Madera), al oeste de San Pablo Chalchihuitán, Estado de Chiapas, México. 1960. El diseño del 
muy destruido fragmento fue reconstruido por Frans Blom. Esta jícara probablemente tuvo la medida de $32 \mathrm{~cm}$ de diámetro.

La relevancia del fragmento es obvia dado que proporciona datos sobre el uso y funcionamiento de la cueva: el jicalpestle nos refiere a un contenedor de comida para quienes participaban en los ritos dedicados a las cabezas y nos sugiere también ofrendas para la Madre Tierra o para el Dueño del Monte, como también se le conoce.

Hacía tiempo que se mencionaba la cueva Monte Virgen, aunque sin referencia a las cabezas. Calnek (1961: 9) reporta que Santa Marta está relacionada tradicionalmente con un sitio arqueológico en la cima de un cerro situado tres leguas al este, cerca del río Chalchihuitán, y que aún se visita con propósitos rituales. Según Calnek, Holland ya había mencionado cómo la tradición consideraba, como un enclave anterior a la conquista española, unas ruinas arqueológicas que se encontraban en el cerro Monte Virgen, en la finca de San Antonio Navarro, en el municipio de Chalchihuitán (Calnek 1961: 23). Holland mismo me confirmó (comunicación personal, 1963), antes de su muerte en Tucson, que la gente de Santa Marta usaba la cueva Monte Virgen.

Como parte de las investigaciones sobre las cabezas de madera de Chalchihuitán, busqué al dueño del rancho antiguo de Monte Virgen en San Cristóbal de Las Casas para ver si podía proporcionarme mayor información sobre las cabezas. Fui a visitar a una vieja amiga de la familia, la señora Julia Penagos de Alcázar (q.e.p.d.), cuyo marido tenía un rancho por el mismo rumbo de Chalchihuitán, y ella me indicó que me entrevistara con el señor Fernando Navarro Ozuna, quien me relató que, cuando era chamaco, subió una vez con su papá y algunos chamulas baldíos del rancho de su papá al Monte Virgen para buscar la cueva.

Las cabezas parecían palos. Mi papá empezó a rebanar una con machete para hacerla más plana para excavar en la cueva. Los indígenas le pararon diciendo que era malo porque llegaban ellos a rezar para lluvia allí y para sanar a sus niños. Que las cabezas eran sagradas. Después los chamulas trataron de quitarle el rancho al dueño, como ya estaban posesionados, pero mi papá logró saber que había delito y una demanda contra el que estaba moviendo a la gente, el Sr. "X", y lo señaló en el mercado de San Cristóbal de Las Casas a la policía y se lo llevaron. La gente se espantó y salió del rancho. Hubo otro chamula de nombre que no se acuerda, quien era capataz del rancho. Después se perdió el rancho en 1960 o 1961 cuando el rancho fue invadido por pableros (de San Pablo Chalchihuitán).

En el rico manuscrito que dejaron Frans Blom y Trudy Duby (1954) sobre el ámbar, el tabaco, el café y los terremotos de Chiapas, encontramos una explicación tseltal que puede tener relación con la tradición de las cabezas en la cueva de Monte Virgen:

En Guaquitepec los tzeltales tienen todavía otra versión sobre el desastre de febrero de este año de 1954: quedaron muchos santos desde antes del diluvio, quedaron enterrados en la tierra, los hay por doquier, pero hay más en el cerro de Ahkabalná, donde había antes un gran templo. Estos santos estaban hechos de palo y con el tiempo se acabaron y donde estaban quedó hueco. Había muchos santos, quedaron muchísimos huecos y por esto se asentó la tierra (Blom y Duby, 1954).

De igual manera, Blom y Duby reportan esta versión chol recolectada en Petalcingo:

Ahkabalná tenía un hijo por casar y le dio mujer sin invitar a los demás cerros. Pero éstos se dieron cuenta después y acudieron para festejar la boda de todas maneras. Vinieron tantos que la tierra no soportó el peso y se sentó y causó los temblores (Blom y Duby, 1954). 
En una carta personal de fecha 20 de octubre de 1967, Trudy me dijo que:

los tzeltales de los que hablaba yo [manuscrito de Blom y Duby] estaban viviendo no lejos de Yajalón y Petalcingo y el cuento me fue relatado por unos indios trabajando en la finca de café al pie de la montaña Ahkabalná (ésta me fue trasladada como la Casa del Señor de la Noche). La finca se llama Hoolbabuchil (cabeza de ámbar), hay mucho ámbar allí, por cierto. Ellos dijeron sobre el terremoto que estaba destruyendo casas en Yajalón y muchas de las fincas en la región, me dijeron que los viejos en el pasado habían escondido sus "santos" hechos de madera debajo del Ahkabalná y cuando se pudrieron después de tantos años la montaña se sentó y causó el terremoto. De hecho se encontró por especialistas que el terremoto entonces, no hace muchos años, no fue debido al volcán sino debido al asentamiento del Ahkabalná.

\section{Las cuevas: espacios sagrados naturales}

Conceptualmente, las aberturas en el suelo, como simas o cuevas en los peñascos y nacimientos de agua, son generalmente conocidas en Mesoamérica como espacios sagrados naturales y son las entradas al Inframundo, donde el "dueño del monte o montaña" vive y controla los naguales de los animales y seres humanos. Esta deidad, conocida entre los mexicas de la época prehispánica como Tepeyolotl, alter ego de Tezcatlipoca, tenía forma de un gran jaguar y era el "corazón del monte" o dueño del Inframundo. Es él a quien todos los seres vivos tienen que pedir permiso para cortar monte, bejucos o juncia; asimismo, hay que solicitar su venia para cazar las aves y animales del bosque, ya que él es el dueño.

Las cuevas son por naturaleza, físicamente, la entrada al subsuelo y, conceptualmente, la entrada al Inframundo y el lugar de los muertos. Son, por lo tanto, lugares sagrados en la religión prehispánica. Hoy día continúa esta antigua tradición porque las cuevas son, de por sí, lugares oscuros, misteriosos y fríos, que siempre se han asociado con la muerte. Son los portales de entrada a la vida después de la muerte. En la época prehispánica, durante todos los periodos fueron lugares por excelencia para el depósito de los muertos y sus ofrendas. Especialmente durante el Posclásico, era costumbre depositar los restos de las cremaciones de los líderes de las comunidades en cántaros de tres asas, junto con lo poco que no se consumió en las llamas fragmentos de dientes, huesos sólidos, así como algunas partes materiales de la ofrenda mortuoria, como obsidiana o metal sobrevivientes a la hoguera también (Lee y Clark 1988: 29-33)-. De acuerdo con Alfonso Villa Rojas (1969: 215), entre los mayas tseltales de Oxchuc, en Chiapas, hasta hace pocas generaciones se conservaba la tradición de colocar a los líderes muertos de la comunidad ya cremados en ollas dentro de cuevas cercanas.

Por su alto significado religioso como lugares sagrados naturales, las cuevas han sido el lugar de muchos ritos y ceremonias de cultos a diferentes aspectos de la vida en Mesoamérica. Aún hoy día las cuevas sirven por doquier en Chiapas y en otros lugares en Mesoamérica como santuarios para ritos de curación o para solicitar bendiciones de salud, amor, fertilidad humana, de siembras o de animales, y bienestar comunitario en general, así como condiciones meteorológicas favorables. La colocación de las cabezas de madera de Chalchihuitán en una cueva concuerda con la tradición de que estos lugares son sagrados y refuerza su importancia como elementos del culto tsotsil local.

\section{Comentarios finales}

Los espacios sagrados naturales y los objetos ahí colocados, como las cabezas coloniales antropomorfas tratadas aquí o los modernos altares con cruces y ofrendas, son ejemplos de la continuidad de conceptos religiosos prehispánicos autóctonos en Mesoamérica. Asimismo, representan resistencias nativas a la religión católica formal y organizada, haciéndose eco de tradiciones 
milenarias y autóctonas de las cuales tenemos aún pocas evidencias.

\section{Notas}

${ }^{1}$ Al saquear el sitio, el Sr. Uke intentaba sacar los dos ídolos descritos en la lámina 2 para los Estados Unidos. Esta violación a las leyes sobre antigüedades de México fue conocida por el autor el 27 de mayo de 1960. El 30 de mayo él y el Dr. Evon Z. Vogt de la Universidad de Harvard, denunciaron al Sr. Uke ante las autoridades del gobierno mexicano en San Cristóbal de Las Casas, Chiapas. Después de algunas semanas, el Sr. Uke fue citado para comparecer ante la Oficina del Ministerio Público de la capital del estado, en Tuxtla Gutiérrez, donde se le imputó la responsabilidad que su acto ameritaba y se le instó a entregar las susodichas piezas. Poco después abandonó el país.

2 Tengo grabaciones en cinta magnética de varias oraciones tsotsiles de curación. Dichas oraciones fueron transcritas hace algún tiempo en dicha lengua y se han traducido al castellano.

\section{Referencias bibliográficas}

Blom, Frans y Gertrude Duby (1954), Las tierras del ámbar, tabaco, café y temblores, San Cristóbal de
Las Casas, Chiapas, México: Biblioteca de Na Bolom (manuscrito inédito).

Bohannan, Paul y Mark Glazer (comp.) (1993), "Las limitaciones del método comparativo de la antropología", en Antropología, lecturas, Madrid: Mc Graw-Hill.

Calneck, Edward (1961), Distribution and Location of the Tzeltal and Tzotzil Pueblos of the Highlands of Chiapas of the Present, Chicago: University of Chicago Man-Land Project (microfilm).

Holland, William R. (1960), "Relaciones entre la religión tzotzil contemporánea y la maya antigua", en Anales del Instituto Nacional de Antropología e Historia, vol. XIII, núm. 42, México: Instituto Nacional de Antropología e Historia/Secretaria de Educación Pública, pp. 113-131.

Lee Whiting, Thomas A. y John E. Clark (1988), "Oro, tela y jute: investigaciones arqueológicas en la región de Camcum, Colonia Las Delicias, Chiapas", en Arqueología, núm. 4, México: Instituto Nacional de Antropología e Historia/Secretaría de Educación Pública, pp. 7-46.

Miranda, Faustino (1998), La vegetación de Chiapas, Tuxtla Gutiérrez, Chiapas, México: Consejo Estatal para la Cultura y las Artes de Chiapas.

Villa Rojas, Alfonso (1969), "The Tzeltal”, en Ethnology, Part One. Handbook of Middle American Indians, vol. 7, Austin: University of Texas Press, pp. 195-225. 
Figura 1. Ídolos de la cueva Monte Virgen, Chalchihuitán, Chiapas, in situ

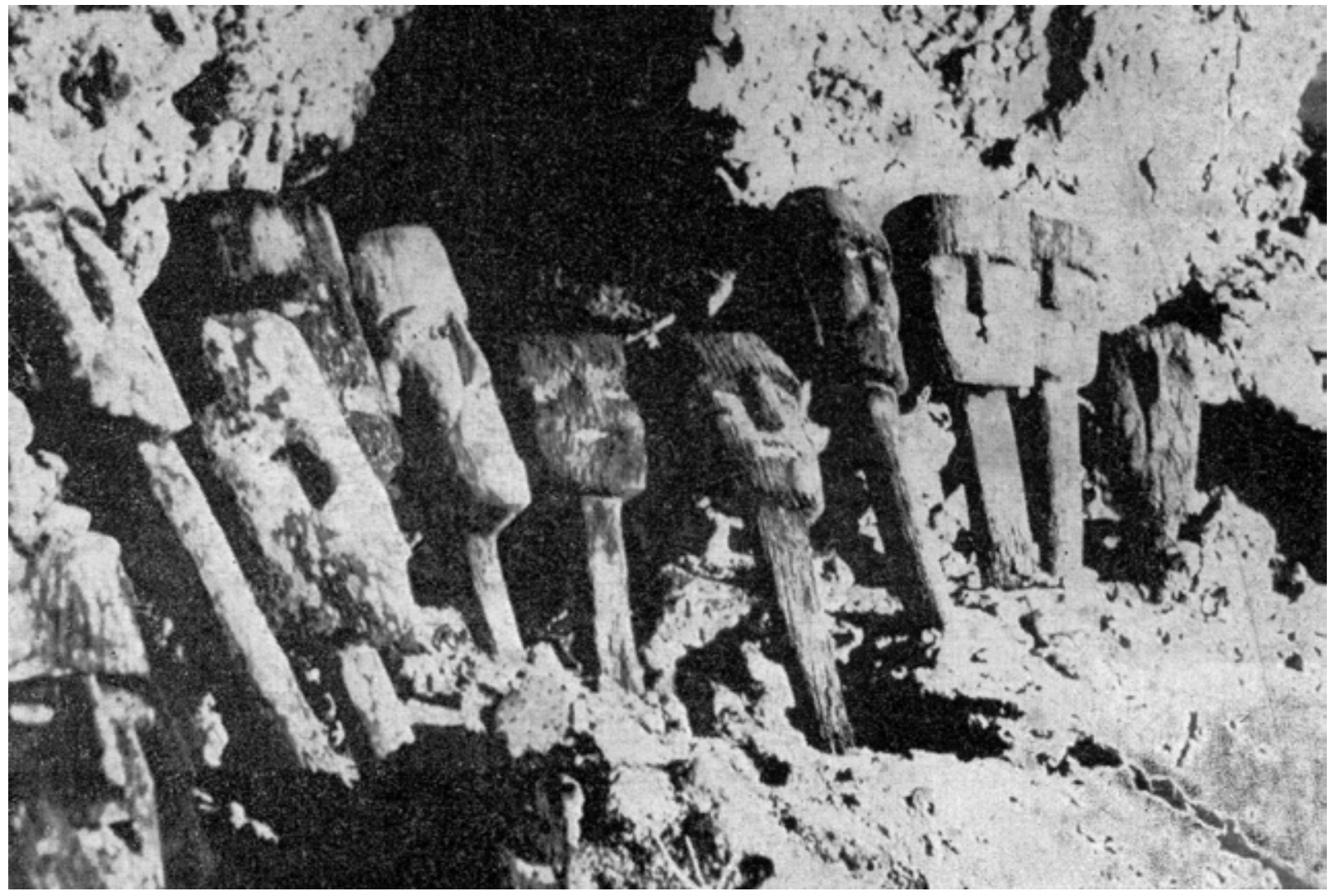

Fuente: Holland (1961), lámina I. 
Figura 2. Clasificación de los ídolos de la cueva Monte Virgen

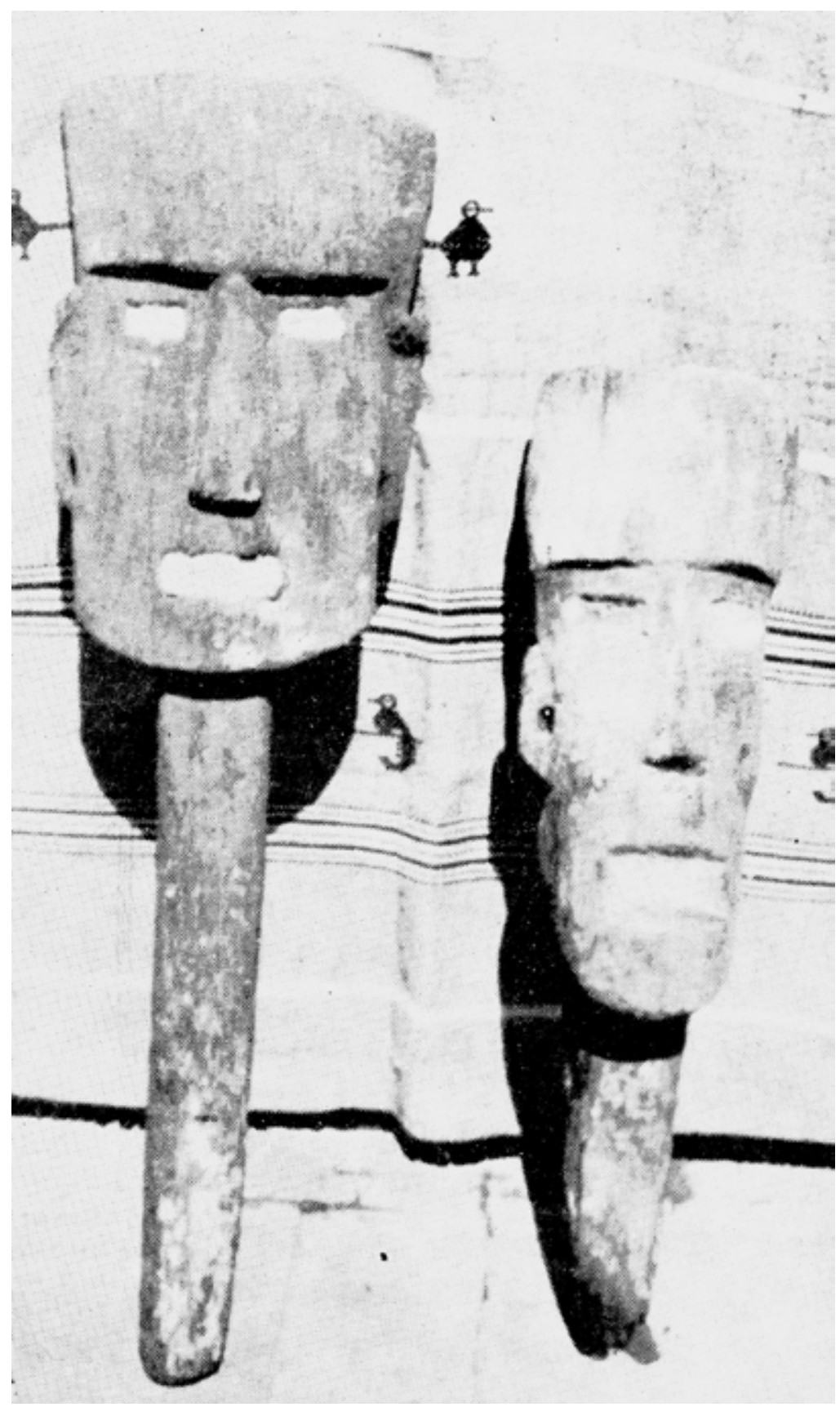

Tipo I (izquierda): longitud: 59.6 centímetros; altura de la cara: 26.6 centímetros; ancho máximo: 17.7 centímetros; espesor de la nariz: 7.6 centímetros. Características: dos agujeros a través de las orejas, incienso en los ojos y en la boca.

Tipo 2 (derecha): longitud: 48.2 centímetros; altura de la cara: 29.2 centímetros; ancho máximo: 12.7 centímetros; espesor en la nariz: 11.4 centímetros. Características: dos agujeros a través de las orejas, uno detrás, incienso en el ojo izquierdo. Fuente: Holland (1961), lámina II. 
Figura 3. Cabezas de madera de la cueva Monte Virgen
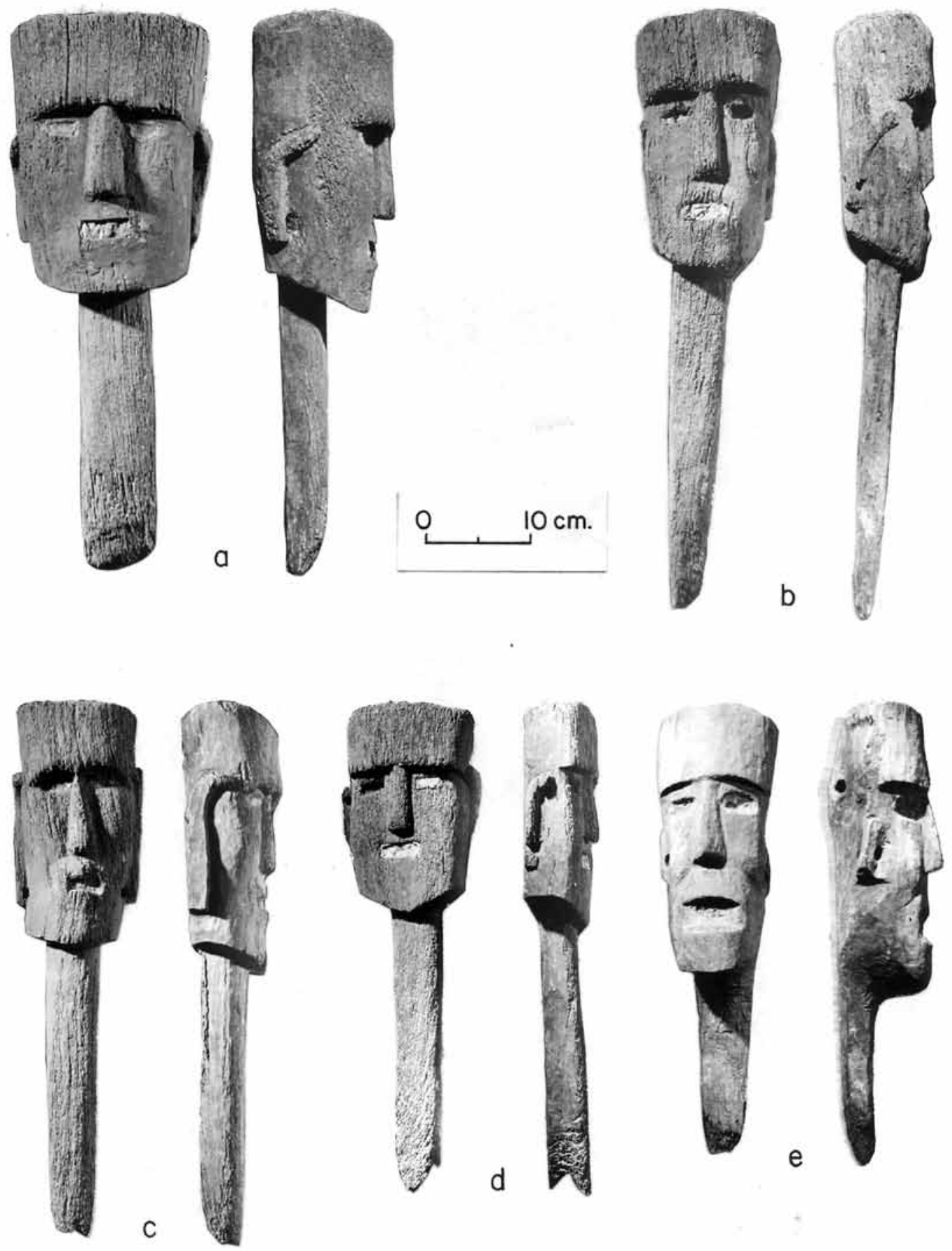

a: Cabeza 1; b: Cabeza 2; c: Cabeza 3; d: Cabeza 4; e: Cabeza 5. 
Figura 4. Cabezas de madera de la cueva de Monte Virgen
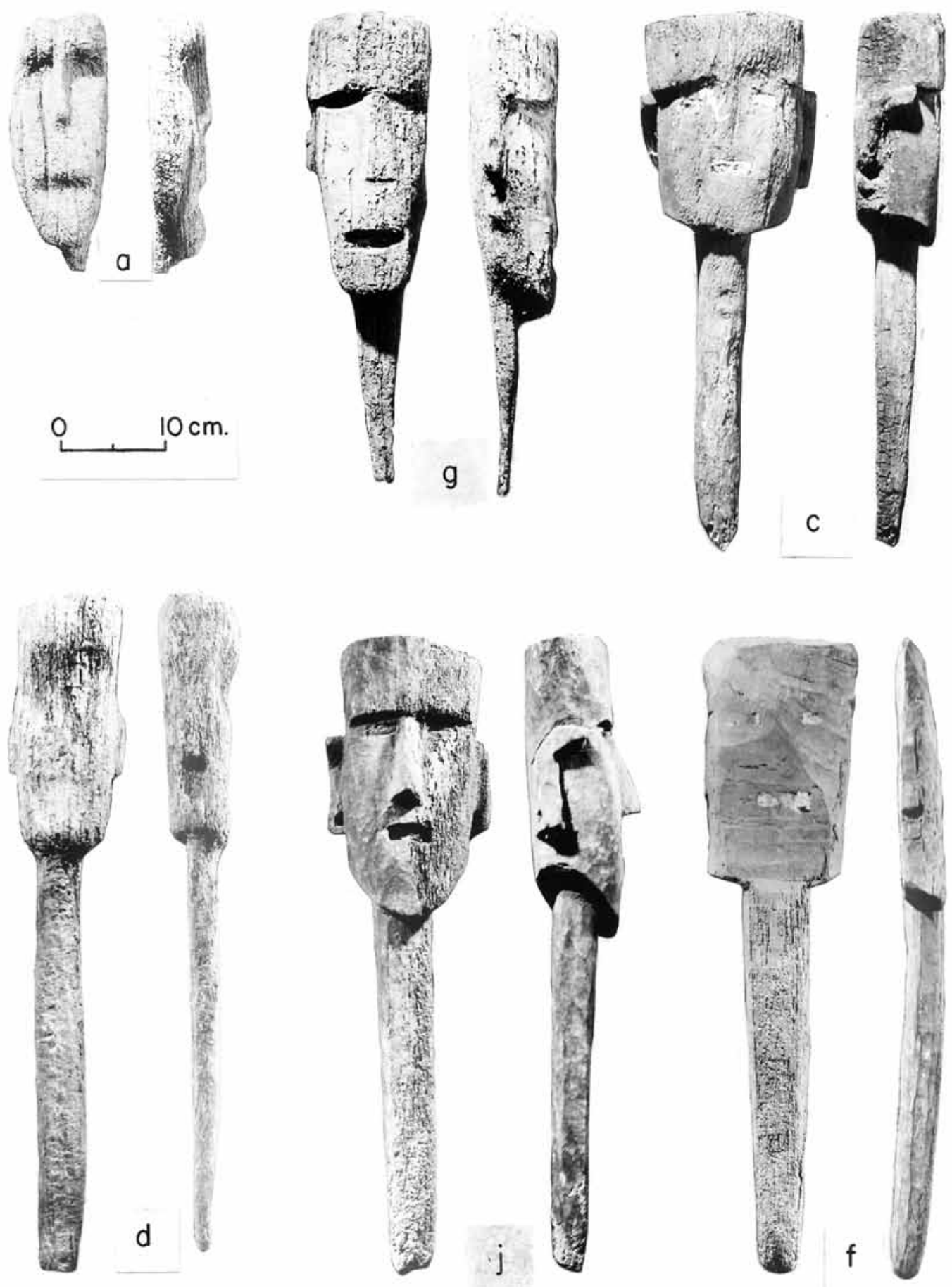

a: Cabeza 6; b: Cabeza 7; c: Cabeza 8; d: Cabeza 9; e: Cabeza 10; f: Cabeza ll. 
Figura 5. Cabezas de madera de la cueva Monte Virgen
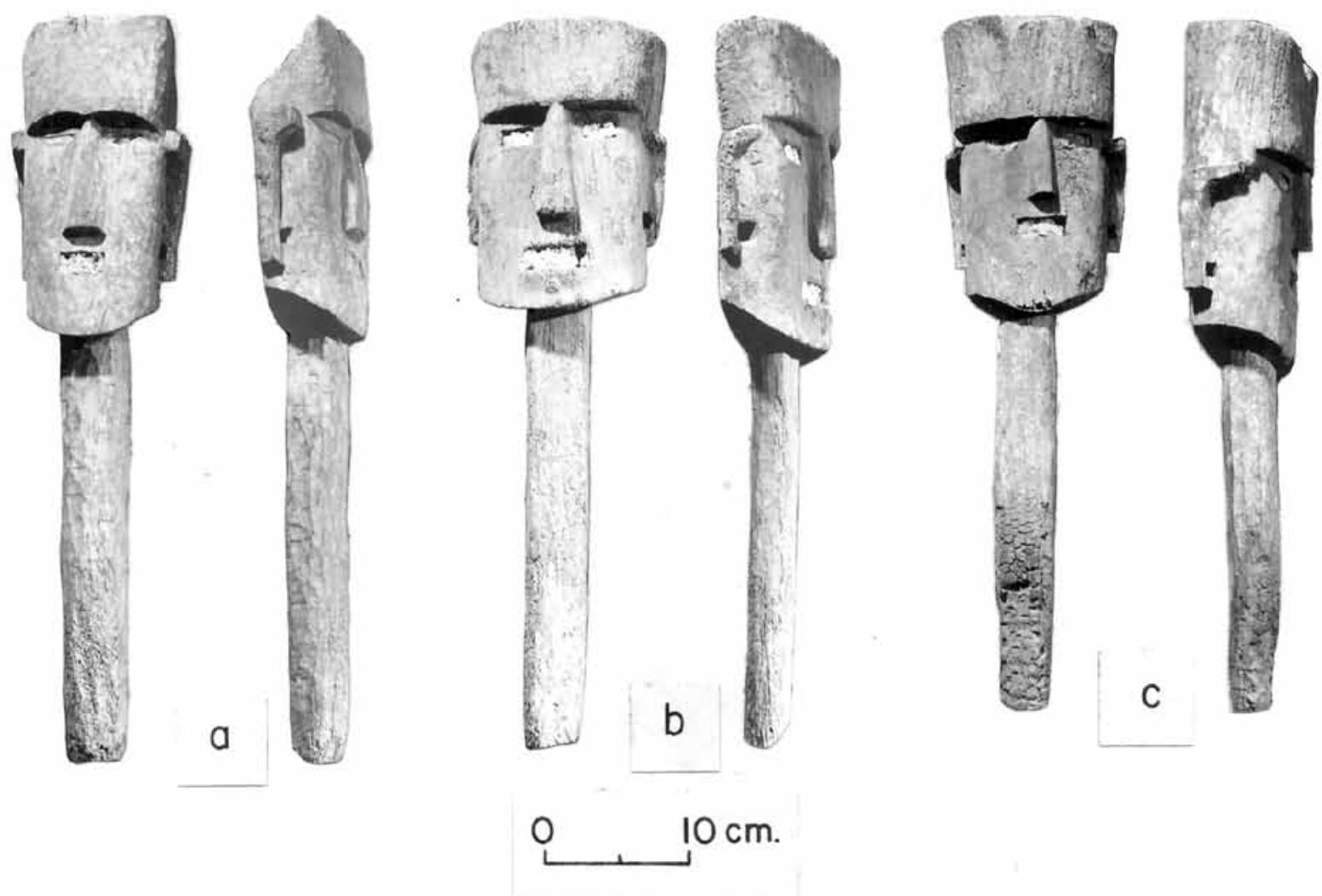

a: Cabeza 12; b: Cabeza 13; c: Cabeza 14. 